\title{
Evaluation of the possible apitherapeutic value of bee venom and bee propolis on L-arginine-induced acute pancreatitis and lung injury in albino rats
}

\begin{abstract}
Introduction: Acute pancreatitis (AP) is a disease that results in inflammation of the pancreatic tissue. The most characteristic features of this disease are activation of digestive enzymes such as amylase and lipase with subsequent release of pro-inflammatory cytokines. It may be complicated with multiorgan failure. Pulmonary complications are considered the most frequent and most serious complications. Apitherapy is a type of natural medicine that uses honey bee products like bee venom and bee propolis for treating various diseases.

The aim of the study: To elucidate the apitherapeutic value of bee venom and bee propolis on L-arginine-induced acute pancreatitis and its associated lung injury complication in adult male albino rats via biological study.

Materials and methods: This study was performed on 70 adult male albino rats. Rats were randomly divided into seven groups: Group I :Control group (CG), Group II :Acute pancreatitis group (AP) in which pancreatitis was induced by two intraperitoneal (i.p.) injections of $2 \mathrm{~g} / \mathrm{kg}$ L-arginine, $1 \mathrm{~h}$ apart, Group III :Bee venom $(250 \mu \mathrm{g} / \mathrm{kg}$ subcutaneous (s.c.) injection) + L-arginine treated group (BVL), Group IV: Bee propolis $(300 \mathrm{mg} / \mathrm{kg}$ intramuscular (i.m.) injection) + L-arginine treated group (BPL), Group V: Combined therapy group (CT), Group VI: Bee venom only treated group(BV) and Group VII: Bee propolis only treated group (BP). The diagnostic markers, including serum lipase and amylase, GGT, glucose, CRP, tissue total antioxidants and RT-PCR analysis of matrix metalloproteinase-9 (MMP-9), were measured. Histological (using hematoxylin \& eosin stain) and Immunohistochemical (using NF- $\mathrm{kB}$ immunostain) techniques were done. The morphometric study was performed for area $\%$ and optical density of immunoexpression of NF- $\mathrm{kB}$ in pancreatic and lung tissues. All performed measurements were followed by statistical analysis.
\end{abstract}

Results: Acute pancreatitis group revealed a significant increase in amylase and lipase serum levels, increase in MMP-9 expression and a decrease in the total antioxidants tissue content. Histopathological results demonstrated widening of the connective tissue septa of the pancreas with degeneration of pancreatic acini in AP group while, the lungs showed thickened interalveolar septa with inflammatory cellular infiltration. A significant increase in immunoreactivity of NF- $\mathrm{kB}$ in pancreatic and lung tissues was also observed. The pretreated groups showed a significant improvement of these biochemical and histological changes.

Conclusions: There was a significant role of pretreatment with bee venom and bee propolis in ameliorating biochemical and histopathological changes in AP group.

Keywords: bee venom, bee propolis, acute pancreatitis, lung injury, 1-arginine, mmp-9, nf-кb
Volume 5 Issue I - 2020

\author{
Sahar Bastawy Ahmed,' Noha Abd El Latif \\ Ibrahim, ${ }^{2}$ Aliaa Ali Hassan, I Nehad Ahmed \\ Sadek, ${ }^{2}$ Maha Khaled Abdelwahed ${ }^{3}$ \\ 'Biochemistry Department, National Organization for Drug \\ Control \& Research, Egypt \\ ${ }^{2}$ Histology Department, Faculty of Medicine, Fayoum University, \\ Egypt \\ ${ }^{3}$ Anatomy Department, Faculty of Medicine, Fayoum University, \\ Egypt
}

Correspondence: Noha Abdellatif Ibrahim, Histology Department, Faculty of Medicine, Fayoum University, Egypt, Tel 01 149939637, Email nohaabdellatif6@gmail.com

Received: December 27, 2019 | Published: January 14, 2020

\section{Introduction}

Acute pancreatitis is a disease that results in inflammation of the pancreas. Activation of digestive enzymes such as amylase and lipase with subsequent release of pro-infammatory cytokines is a characteristic feature of the disease. ${ }^{1}$ The markers used for diagnosis of acute pancreatitis include amylase, lipase, trypsinogen, interleukin-6 and $\mathrm{C}$ reactive protein. ${ }^{2}$ The inflammatory condition may be limited to the pancreatic gland, or it may extend to involve the surrounding tissues and/or distant organs. Hence, the clinical manifestations range from mild abdominal pain to very serious presentations. ${ }^{3}$ L-Arginine is an amino acid that increases the muscular power and improves performance through maintaining ATP level. In spite of this, 1-arginine was found to induce acute pancreatitis in animals. ${ }^{4}$

One of the most common animal models used to study the biochemical and histological alterations of AP was L-arginineinduced acute pancreatitis. It induced pancreatitis in rats by oxygen 
and nitrogen free radicals generation which in turn distort the cellular membranes of zymogen granules. This results in releasing the digestive enzymes, cellular proteins, and increased levels of inflammatory mediators. 5

Honeybees products include numerous substances such as bee venom, bee propolis, bee pollen, and royal jelly. They are known to have many medicinal and health-promoting properties. Bee products are a great source of natural antioxidants. They contain flavonoids, phenolic acids, or terpenoid. ${ }^{6}$ So, the use of natural substances that having the ability to counteract the effects of oxidative stress that underlie the pathogenesis of numerous diseases, such as neurodegenerative disorders, cancer, diabetes, and atherosclerosis, and to combat the negative effects of different harmful factors and drugs become a great concern.

Honeybees (Apis mellifera) produce a natural toxin known as bee venom. Purified bee venom is well known for its anti inflammatory, analgesic and anti-cancer effects. ${ }^{8}$ Bee venom contains different peptides such as melittin, apamin, adolapamin and mast cell degranulating peptide. It was claimed to stimulate cortisol secretion and to enhance antibody production. It also modulates cytokine production. ${ }^{9}$

Propolis is another honeybee product. Its chemical composition was very complex. It has an antioxidant property due to its high content of polyphenolic components including flavonoids, tannins, terpenoids and phenolic compounds. These compounds have freeradical scavenging activity. Many biological and pharmacological properties of propolis have been noted. They include antibacterial, antifungal, anti-inflammatory, antioxidant, immunomodulatory, antiviral and anticarcinogenic properties..$^{10,11}$

Apitherapy is a type of natural medicine that uses honeybee products, including honey, pollen, propolis, royal jelly and bee venom. As modern medicine has sometimes either many side effects or inefficient curative effect, so, we were looking back to the past for an alternative approach like apitherapy. ${ }^{12,13}$ So, the aim of this study was to evaluate the possible apitherapeutic value of bee venom and bee propolis on L-arginine-induced acute pancreatitis and its associated lung injury in adult male albino rats using biochemical, histological and immuno-histochemical techniques.

\section{Materials and methods}

Animals: Seventy adult male albino rats, locally bred at the Animal House of Kasr El Aini with an average weight of 200-250 g were used in the present study. Rats were housed at ordinary room temperature, exposed to natural daily light-dark cycles, had access to food and water ad libitum. This experiment has been approved by the ethics committee for animal research in the animal house of Kasr-El-Aini Faculty of Medicine, Cairo University, Egypt following international ethics and regulations for animal research in laboratory applications. ${ }^{14}$

\section{Experimental design}

The animals were divided into seven groups:

Group I (Control group) (CG): Included ten rats that were further divided into untreated rats, and that received the same solvents of the drugs in injection form at the same times with the experimental animals. All rats were sacrificed at the same time as the corresponding experimental group.

Group II (Acute pancreatitis group) (AP): Included ten rats which were injected intraperitoneally (i.p.) with L-Arginine (Sigma-Aldrich, St. Louis, MO, USA) in two doses of $2 \mathrm{~g} / \mathrm{kg}$ body weight each, $1 \mathrm{~h}$ apart. L-arginine was dissolved in normal saline. ${ }^{15}$

Group III (Bee venom+L-arginine group) (BVL): Included ten rats which were given $250 \mu \mathrm{g} / \mathrm{kg}$ bee venom (Vacsera) dissolved in normal saline by subcutaneous injection (s.c.) one hour before injection of L-arginine and 24 hours after the second dose of L-arginine..$^{16,17}$

Group IV (Bee propolis $+\mathrm{L}$-arginine group) (BPL): Included ten rats which were given $300 \mathrm{mg} / \mathrm{kg}$ bee propolis (Biopropolis, Sigma, Egypt) dissolved in buffer phosphate saline by intramuscular injection (i.m.) one hour before injection of L-arginine and 24 hours after the second dose of L-arginine. ${ }^{18}$

Group V (Combined thaerapy group) (CT): Included ten rats which were given both bee propolis and bee venom one hour before injection of L-arginine and 24 hours after the second dose of 1-arginine.

Group VI (Bee venom only treated group) (BV): Included ten rats which were given two doses of $250 \mu \mathrm{g} / \mathrm{kg}$ bee venom (Vacsera) dissolved in normal saline by subcutaneous injection on the first and second day of the experiment.

Group VII (Bee propolis only treated group) (BP): Included ten rats which were given two doses of $300 \mathrm{mg} / \mathrm{kg}$ bee propolis (Biopropolis, Sigma, Egypt) dissolved in buffer phosphate saline by intramuscular injection on the first and second day of the experiment.

\section{Preparation of blood and tissues for biochemical analysis}

After 48 hours after the second injection of 1-arginine, the rats were anesthetized using an injection of thiopental sodium $50 \mathrm{mg} / \mathrm{kg}$ subcutaneously. The blood samples were directly taken from retinoorbitalpuncture and were centrifuged at $3000 \mathrm{rpm}$ for $15 \mathrm{~min}$. The collected serum was stored at $-70^{\circ} \mathrm{C}$. The pancreas and lungs were quickly removed and fixed in formaldehyde $(10 \%)$ for histological examination. Remaining parts of pancreatic tissues were frozen until needed for Total Antioxidant Capacity (TAC) and total RNA extraction and gene expression. The supernatants of blood used for measurement of CRP according to Fisher et al., ${ }^{19}$ amylase by diagnostic kit colorimetric method according to ${ }^{20}$ lipase colorimetric method by Spectrum kit, ${ }^{21}$ GGT by Spectrum kit kinetic colorimetric according to Szasz method, ${ }^{22}$ glucose levels by enzymatic colorimetric according to Weissman et al. ${ }^{23}$ Caraway et al. ${ }^{24}$ Total Antioxidant Capacity (TAC) was measured in pancreatic tissue, using Randox (Shanghi, China) kit Total Antioxidant Capacity, (cat No. Nx 2331) according to the method of ${ }^{25}$ and expressed as nmol TAC/g tissue.

\section{Quantitative analysis of gene expression of MMP-9 by real time PCR}

\section{Total RNA extraction}

Total RNA was extracted from tissue homogenate using SV Total RNA Isolation System (Promega, Madison, WI, USA) according to manufacturer's instruction. The RNA concentrations and purity were measured with an ultraviolet spectrophotometer. 


\section{Complementary DNA (cDNA) synthesis}

The cDNA was synthesized from $1 \mu \mathrm{g}$ RNA using SuperScript III First-Strand Synthesis System as described in the manufacturer's protocol (\#K1621, Fermentas, Waltham, MA, USA). One $\mu \mathrm{g}$ of total RNA was mixed with $50 \mu \mathrm{M}$ oligo (dT) $20,50 \mathrm{ng} / \mu \mathrm{L}$ random primers, and $10 \mathrm{mM}$ dNTP mix in a total volume of $10 \mu \mathrm{L}$. Then the mixture was incubated at $56^{\circ} \mathrm{C}$ for $5 \mathrm{~min}$, and placed on ice for $3 \mathrm{~min}$. The reverse transcriptase master mix containing $2 \mu \mathrm{L}$ of $10 \times$ RT buffer, 4 $\mu \mathrm{L}$ of $25 \mathrm{mM} \mathrm{MgCl} 2,2 \mu \mathrm{L}$ of $0.1 \mathrm{M}$ DTT, and $1 \mu \mathrm{L}$ of SuperScript ${ }^{\circledR}$ III RT $(200 \mathrm{U} / \mu \mathrm{L})$ was added to the mixture and incubated at $25^{\circ} \mathrm{C}$ for $10 \mathrm{~min}$ followed by $50 \mathrm{~min}$ at $50^{\circ} \mathrm{C}$.

\section{Real-time quantitative PCR}

Real-time PCR amplification and analysis were performed using an Applied Biosystem with software version 3.1 (StepOne ${ }^{\mathrm{TM}}$, USA). The reaction contained SYBR Green Master Mix (Applied Biosystems), gene-specific primer pairs which were shown in Table 1 and were designed with Gene Runner Software (Hasting Software, Inc., Hasting, NY) from RNA sequences from the gene bank. All primer sets had a calculated annealing temperature of $60^{\circ} \mathrm{C}$. Quantitative RT-PCR was performed in a $25-\mu 1$ reaction volume consisting of $2 \mathrm{X}$ SYBR Green PCR Master Mix (Applied Biosystems), $900 \mathrm{nM}$ of each primer and $2 \mu \mathrm{l}$ of cDNA. Amplification conditions were: $2 \mathrm{~min}$ at $50^{\circ} \mathrm{C}, 10 \mathrm{~min}$ at $95^{\circ} \mathrm{C}$ and 40 cycles of denaturation for $15 \mathrm{~s}$ and annealing/extension at $60^{\circ} \mathrm{C}$ for $10 \mathrm{~min}$. Data from real-time assays were calculated using the v1.7 sequence detection software from PE Biosystems (Foster City, CA). Relative expression of studied gene mRNA was calculated using the comparative $\mathrm{Ct}$ method. All values were normalized to GAPDH which was used as the control housekeeping gene and reported as fold change over background levels detected in the diseased groups.

The primer sequence of the studied gene MMP-9:

Forward primer: 5'- CCA CCG AGC TAT CCA CTC AT -3

Reverse primer: 5'- GTC CGG TTT CAG CAT GTT TT -3

The primer sequence of the studied gene GAPDH:

Forward primer :5'-- TGAACGGGAAGCTCACTGG -3

Reverse primer:5'- TCCACCACCCTGTTGCTGTA

\section{Histopathology and Immunohistochemical study}

Specimens of pancreas and lung tissues were dehydrated processed to obtain paraffin blocks. Five $\mu \mathrm{m}$ sections were cut and stained with H\&E stain. Immunohistochemical staining was done using anti NF-kB/p65 (Labvision, Thermo Scientific, USA) rabbit polyclonal antibody, catalog no. RB -1638. The reaction is cytoplasmic and the + ve control was the prostate.

\section{Morphometric study}

The morphometric data were obtained using the image analyzer computer system (Leica Qwin 500, England). The area \% and optical density of NF-kB/p65 immunoexpression were measured in 10 high power $(\mathrm{x} 40)$ non- overlapping fields in each specimen using binary mode.

\section{Statistical analysis}

The data were expressed as group means \pm SEM after checking for normality of distribution. The statistical analysis was carried out using ANOVA followed by Tukey post hoc test, with SPSS version 16 (SPSS, Chicago, IL, USA). A value of $\mathrm{p} \leq 0.05$ was accepted as statistically significant.

\section{Results}

\section{Biochemical results}

There was a significant elevation $(\mathrm{P} \leq 0.05)$ in amylase, lipase activity and glucose in AP group as compared with control and other pretreated groups. There was no significant difference between the pretreated groups (Table 1).

Regarding GGT and CRP, there was a significant increase $(\mathrm{P}<0.05)$ in their levels in AP, BVL, BPL and CT groups as compared to the control group. On the other hand, a significant decrease in GGT and CRP levels was noticed in the BVL, BPL and CT groups compared to AP group. There was no significant difference between the pretreated groups (Table 2).

Table 3 cleared up that there was a significant decrease $(\mathrm{P}<0.05)$ in $\mathrm{TAC}$ level in AP and all pretreated groups as compared to the control group. However, there was a significant improvement in pretreated groups when compared with AP group. Combined therapy group showed significant increase in TAC as compared with single therapy groups (BVL and BPL).

Table I Effectiveness of various treatments on serum amylase, lipase enzymes activity and glucose level in rats. Data presented as mean \pm SE

\begin{tabular}{|c|c|c|c|c|c|c|c|}
\hline BP & BV & CT & BPL & BVL & AP & CG & $\begin{array}{l}\text { Treatment } \\
\text { measurement }\end{array}$ \\
\hline $1234.5 \pm 13.4$ & $1230.9 \pm 10.4$ & $1202 \pm 3.06^{\mathrm{b}}$ & $1180 \pm 15.1^{b}$ & $1233 \pm 16.2^{b}$ & $1450 \pm 3.1^{\mathrm{a}}$ & $1238.9 \pm 17.1$ & Amylase (U/I) \\
\hline $22.1 \pm 1.1$ & $20.2 \pm 0.9$ & $26.2 \pm 1.4^{b}$ & $23.3 \pm 1.48^{b}$ & $19.9 \pm 1.7^{\mathrm{b}}$ & $63.2 \pm 0.6^{a}$ & $21.2 \pm 1.09$ & Lipase (U/l) \\
\hline $103.9 \pm 3.8$ & $111.01 \pm 1.6$ & $143.8 \pm 2.5^{\mathrm{a}, \mathrm{b}}$ & $\mid 48.3 \pm 2.6^{\mathrm{a}, \mathrm{b}}$ & $154.2 \pm 4.7^{\mathrm{a}, \mathrm{b}}$ & $163.7 \pm 2.7^{\mathrm{a}}$ & $108.2 \pm 3.9$ & Glucose $(\mathrm{mg} / \mathrm{dl})$ \\
\hline
\end{tabular}

a, $P \leq 0.05$, significant difference as compared to the control

$b, P \leq 0.05$, significant difference compared to AP 
Table 2 Effectiveness of various treatments on Serum levels GGT andCRP after L-arginine induced acute pancreatitis. Data presented as mean \pm SE

\begin{tabular}{|c|c|c|c|c|c|c|c|}
\hline BP & BV & CT & BPL & BVL & $\mathbf{A P}$ & CG & $\begin{array}{l}\text { Treatments } \\
\text { measurements }\end{array}$ \\
\hline $1.87 \pm 0.09$ & $2.01 \pm 0.12$ & $3.6 \pm 0.06^{a, b}$ & $4.16 \pm 0.09^{a, b}$ & $4.08 \pm 0 . I^{\mathrm{a}, \mathrm{b}}$ & $6.3 \pm 0.16^{a}$ & $1.9 \pm 0.12$ & GGT (U/I) \\
\hline $6.7 \pm 3.6$ & $6 \pm 4.8$ & $60.04 \pm 20.6^{\mathrm{a}, \mathrm{b}}$ & $55.06 \pm 15.0^{\mathrm{a}, \mathrm{b}}$ & $54.08 \pm 16.0^{\mathrm{a}, \mathrm{b}}$ & $80.04 \pm 31,0^{a}$ & $7.4 \pm 6.3$ & CRP (mg/l) \\
\hline
\end{tabular}

a, $P \leq 0.05$, significant difference as compared to the control

$b, P \leq 0.05$, significant difference compared to $A P$

Table 3 Total antioxidant capacity. Data presented as mean \pm SE

\begin{tabular}{|c|c|c|c|c|c|c|c|}
\hline BP & BV & CT & BPL & BVL & APG & CG & $\begin{array}{l}\text { Treatments } \\
\text { measurements }\end{array}$ \\
\hline $27.9 \pm 0.28$ & $29.2 \pm 0.15$ & $21.4 \pm 0.16^{\mathrm{a}, \mathrm{b}}$ & $19.3 \pm 0.15^{\mathrm{a}, \mathrm{b}, \mathrm{c}}$ & $18.3 \pm 0.18^{a, b, c}$ & $12.06 \pm 0.04^{\mathrm{a}}$ & $28.9 \pm 0.18$ & TAC (nmol/gm tissue) \\
\hline
\end{tabular}

$a, P \leq 0.05$, significant difference as compared to the cont

$b, P \leq 0.05$, significant difference compared to $A P$

$c, P \leq 0.05$, significant difference compared to combined therapy

Table 4 Mean \pm SE area \% and optical density of NF-KB in pancreas

\begin{tabular}{|c|c|c|c|c|c|c|c|}
\hline $\mathbf{B P}$ & BV & CT & BPL & BVL & AP & CG & Treatments measurements \\
\hline $\mathrm{I} . \mathrm{I} \pm 0.006$ & $\begin{array}{l}1.02 \pm \\
0.006\end{array}$ & $1.5 \pm 0.09^{b}$ & $\begin{array}{l}3.02 \pm \\
0.03^{\mathrm{a}, \mathrm{b}}\end{array}$ & $\underset{\mathrm{a}, \mathrm{b}}{2.8 \pm 0.006}$ & $4.6 \pm 0.4 I^{a}$ & $\begin{array}{l}1.2 \pm \\
0.006\end{array}$ & Area $\%$ of NF-KB in pancreas \\
\hline $\begin{array}{l}0.25 \pm \\
0.003\end{array}$ & $\begin{array}{l}0.23 \pm \\
0.009\end{array}$ & $\begin{array}{l}0.27 \pm \\
0.03^{b}\end{array}$ & $0.6 \pm 0.003^{\mathrm{a}, \mathrm{b}}$ & $0.45 \pm 0.0 I^{a, b}$ & $\begin{array}{l}1.2 \pm \\
0.009^{a}\end{array}$ & $0.2 \pm 0.01$ & $\begin{array}{l}\text { Optical density of NF-KB in } \\
\text { pancreas }\end{array}$ \\
\hline
\end{tabular}

$a, P \leq 0.05$, significant difference as compared to the control

$b, P \leq 0.05$, significant difference compared to $A P$

Table 5 Mean \pm SE area \% and optical density of NF-KB in lung

\begin{tabular}{|c|c|c|c|c|c|c|c|}
\hline BP & BV & CT & BPL & BVL & AP & CG & $\begin{array}{l}\text { Treatments } \\
\text { measurements }\end{array}$ \\
\hline $\begin{array}{l}0.24 \pm \\
0.022\end{array}$ & $\begin{array}{l}0.21 \pm \\
0.009\end{array}$ & $\begin{array}{l}0.64 \pm \\
0.003^{\mathrm{a}, \mathrm{b}}\end{array}$ & $\begin{array}{l}I . I \pm \\
0.006^{a, b}\end{array}$ & $\begin{array}{l}0.53 \pm \\
0.0 I^{\mathrm{a}, \mathrm{b}}\end{array}$ & $10 \pm 0.07^{a}$ & $\begin{array}{l}0.23 \pm \\
0.003\end{array}$ & Area $\%$ of NF-KB in lung \\
\hline $\begin{array}{l}0.39 \pm \\
0.006\end{array}$ & $0.4 \pm 0.03$ & $0.44 \pm 0.03 \mathrm{I}^{\mathrm{b}}$ & $\begin{array}{l}0.46 \pm \\
0.003^{b}\end{array}$ & $\begin{array}{l}0.42 \pm \\
0.012^{b}\end{array}$ & $\begin{array}{l}1.7 \pm \\
0.006^{\mathrm{a}}\end{array}$ & $\begin{array}{l}0.41 \pm \\
0.003\end{array}$ & $\begin{array}{l}\text { Optical density of NF- } K B \text { in } \\
\text { lung }\end{array}$ \\
\hline
\end{tabular}

a, $P \leq 0.05$, significant difference as compared to the control

$b, P \leq 0.05$, significant difference compared to $A P$

Matrix metalloproteinase-9 showed a significant increase in expression (6.8 folds) in AP group as compared with the control and the pretreatment groups. There was also a significant increase in expression in BVL (2.6 folds), BPL (2.8 folds) and CT (1.4 folds) groups as compared with the control rats. Combined therapy group showed a significant decrease in MMP-9 expression as compared with the single therapy groups. A correlation was observed between MMP9 expression and degree of pancreatitis (Graph).

Bee venom and bee propolis only treated rats showed no significant difference as compared with the control in all parameters.

\section{Histological results}

\section{Hematoxylin\& eosin results}

Pancreas: Examination of hematoxylin \& eosin - stained sections of the control pancreatic specimens showed the characteristic appearance of pancreatic acini with apical acidophilic granules and basal basophilia. Lightly-stained islets of Langerhans were seen in between the acini (Figures $1 \mathrm{a} \& 1 \mathrm{~b}$ ). The specimens from the AP group revealed distortion and vacuolation of pancreatic acinar cells, widening in the connective tissue septa (Figure 2). They also demonstrated congested blood vessels with acidophilic material inside, extravasation of RBCs and infiltration of mononuclear inflammatory cells in the connective tissue septa and blood vessels (Figure 3). Regarding pancreatic sections of bee venom pretreated rats (BVL group), they appeared nearly as that of the control group with the characteristic acini and islets of Langerhans preserved (Figures $4 \mathrm{a} \& 4 \mathrm{~b}$ ). Bee propolis pretreated rats (BPL group) showed mild distortion in pancreatic acini (Figures $5 \mathrm{a} \& 5 \mathrm{~b}$ ). Combined therapy treated rats (CT group) revealed marked improvement with no wideninig in the connective tissue septa or distortion of pancreatic acini. Few acini showed some vacuolated cells (Figures 6a\&6b). In bee venom only treated rats (BV group), they appeared normal compared to the control group (Figure 7). No remarkable difference was observed in propolis only treated rats (BP group) compared with group VI. 


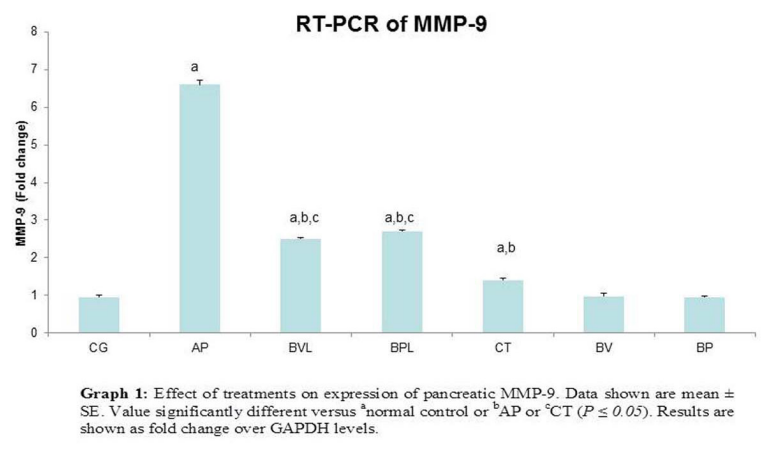

Graph Effect of treatments on expression of pancreatic MMP-9. Data shown are mean \pm SE. Value significantly different versus ${ }^{a}$ normal control or ${ }^{b} A P$ or ${ }^{c} \mathrm{CT}(P \leq 0.05)$. Results are shown as fold change over GAPDH levels.
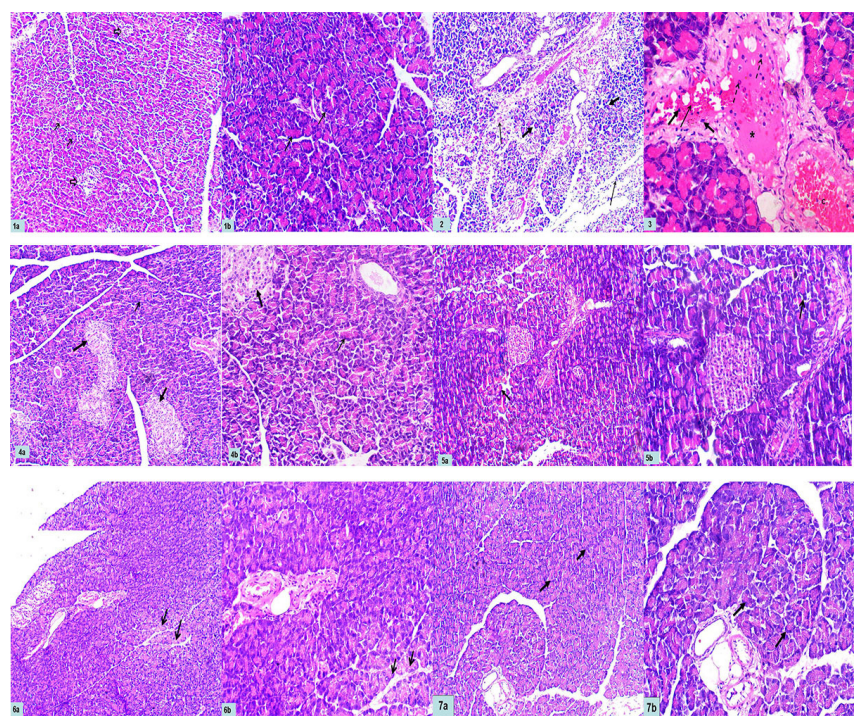

Figures Ia\&b Photomicrographs of a section of a rat pancreas in group I (CG) showing the characteristic appearance of pancreatic acini (thin arrows) with apical acidophilic granules and basal basophilia. Lightly stained islets of Langerhans (thick arrows) are seen in between the acini.

a-Hx. \&E; x 100

b- Hx. \&E; x 200

Figure 2 A Photomicrograph of a section of a rat pancreas in group II (AP group) showing distortion and vacuolation of pancreatic acinar cells (thick arrows), widening in the connective tissue septa (thin arrows).

Hx. \&E; x 100

Figure 3 A Photomicrograph of a section of a rat pancreas in group II (AP group) showing congested blood vessels (C), extravasation of RBCs (thin arrow) and infiltration of mononuclear inflammatory cells in the connective tissue septa (thick arrows) and blood vessels (dotted arrows). Notice the acidophilic material in the blood vessel $\left(^{*}\right)$.

Hx. \&E; x 400

Figures $4 \mathbf{a} \& \mathbf{b} \mathrm{A}$ photomicrographs of a section of a rat pancreas in group III (BVL group) showing preserved acini (thin arrows) and islets of Langerhans (thick arrows) which appear nearly as that of the control group.

a-Hx. \&E; $x 100$

b-Hx. \&E; x 200
Figures $\mathbf{5 a \& b}$ Photomicrographs of a section of a rat pancreas in group IV (BPL group) showing mild distortion in pancreatic acini (arrows).

a-Hx. \&E; x 100

b- Hx. \&E; x 200

Figures $\mathbf{6 a \boldsymbol { a } \mathbf { b }}$ Photomicrographs of a section of a rat pancreas in group $\checkmark$ (CT group) showing marked improvement with no wideninig in the connective tissue septa or distortion of pancreatic acini. Few acini showed some vacuolated cells (arrows).

a-Hx. \&E; x 100

b- Hx. \&E; $x 200$

Figures 7a\&b Photomicrographs of a section of a rat pancreas in groups $\mathrm{VI}$ (BVgroup) showing normal acini (arrows) comparable with the control group. Hx. \&E; x 100

\section{Lung}

The hematoxylin\& eosin - stained sections of control lung specimens showed normal-appearing lung architecture with expanded alveoli separated by thin interalveolar septa and members of the bronchial tree in between (Fig. 8). Lung specimens from the AP group demonstrated thickened interalveolar septa and dilated congested blood vessels with acidophilic hyaline exudate. There was also acidophilic material in the bronchiolar lumen. Inflammatory cellular infilteration in addition to collapsed alveoli were observed (Figures 9\&10a,\&10b).

Regarding lung sections of bee venom pretreated rats (BVL group), they showed normal expanded alveoli with thin interalveolar septa with intrabronchiolar congestion (Figure 11). Bee propolis pretreated rats (BPL group), they showed areas of expanded alveoli with thin interalveolar septa. Other areas showed thickened interalveolar septa in addition to presence of dilated congested blood vessels with acidophilic hyaline exudate (Figure 12). Combined therapy treated rats (CT group) revealed marked improvement with expanded alveoli and thinning of interalveolar septa. Disappearance of congestion and inflammatory cellular infiltration was observed (Figure 13).

In bee venom only treated rats (BV group), they appeared normal compared to the control group (Figure 14). No remarkable difference was observed in propolis only treated rats (BP group) compared with group VI.

\section{Immunohistochemical}

\section{Pancreas}

NF- $\kappa \mathrm{B}$ immuno-stained sections of control pancreas demonstrated mild cytoplasmic immunoexpression in the acinar cells (Figure 15), while, AP group showed intense cytoplasmic and nuclear immunoreactivity in the acinar cells (Figures 16a\&16b). Regarding pancreatic sections of bee venom pretreated rats (BVL group), they showed moderate cytoplasmic immunoreaction in the acinar cells (Figure 17). Bee propolis pretreated rats (BPL group) showed positive cytoplasmic immunoreaction in pancreatic acini and negative immunoreaction in islet of Langerhans (Figure 18). Combined therapy treated rats (CT group) revealed positive cytoplasmic immunoreaction in pancreatic acini (Figure 19).

In bee venom only treated rats (BV group), they showed mild immunoreaction in acinar cells (Figure 20). No remarkable difference was observed in bee propolis only treated rats (BP group) compared with group VI. 


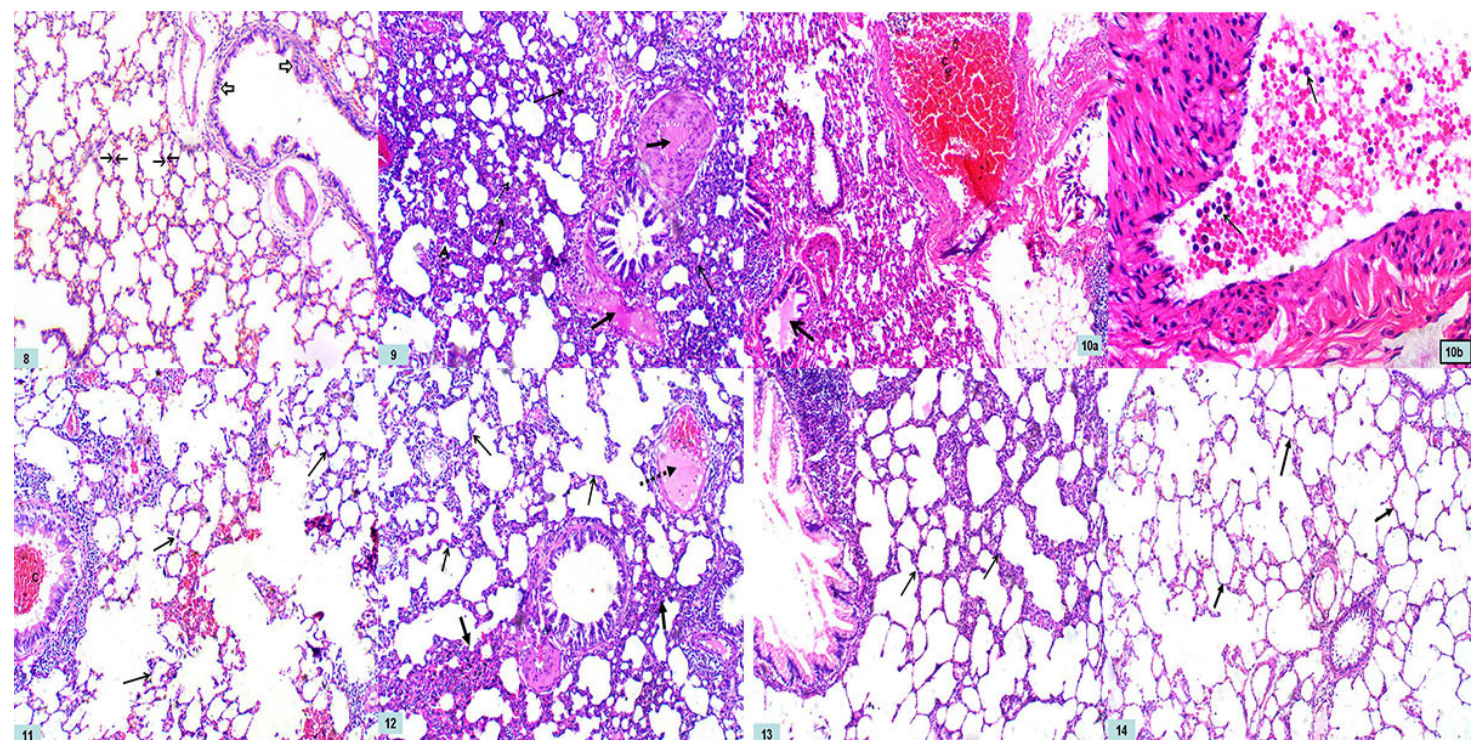

Figure $8 \mathrm{~A}$ photomicrograph of a section of a rat lung in group I (CG) showing normal-appearing lung architecture with the expanded alveoli separated by thin interalveolar septa (thin arrows) and members of the bronchial tree in between (thick arrows).

Hx. \&E; x 100

Figure 9 A photomicrograph of a section of a rat lung in group II (AP group) showing thickened interalveolar septa (thin arrows) and acidophilic hyaline exudate in the blood vessels (thick arrows). Collapsed alveoli are observed (dotted arrows).

Hx. \&E; x 100

Figures I $\mathbf{0 a \& b}$ Photomicrograph of a section of a rat lung in group II (AP group) showing mononuclear inflammatory cellular infiltrate (thin arrows) inside dilated and congested $(\mathrm{C})$ blood vessels. There is also acidophilic material in bronchiolar lumen (thick arrows).

a- Hx. \&E; $x 100$

b- Hx. \&E; 400

Figure I I A photomicrograph of a section of a rat lung in group III (BVL group) showing normal expanded alveoli with thin interalveolar septa (arrows) with intrabronchiolar congestion (C).

Hx. \&E; x 100

Figure I 2 A photomicrograph of a section of a rat lung in group IV (BPL group) showing areas of expanded alveoli with thin interalveolar septa (thin arrows). Other areas showed thickened interalveolar septa (thick arrows) in addition to presence of dilated congested blood vessels with acidophilic hyaline exudate (dotted arrow).

Hx. \&E; x 100

Figure I 3 A photomicrograph of a section of a rat lung in groupV (CT group) showing marked improvement with expanded alveoli and thinning of interalveolar septa (arrows). Disappearance of congestion and inflammatory cellular infiltration is observed.

Hx. \&E; x 100

Figure I4 A photomicrograph of a section of a rat lung in groups VI (BV group) showing normal appearance of alveoli and interalveolar septa (arrows) comparable with the control group.

Hx. \&E; x 100

\section{Lung}

NF-kBimmuno-stained sections of control lung specimens demonstrated mild positive cytoplasmic immunoexpression in the epithelial cells lining the expanded alveoli, bronchioles, as well as in the cells of connective tissue septa (Figure 21). The lungs of the AP group were characterized by the presence of intense cytoplasmic immunoreactivity in the epithelial cells lining the alveoli, bronchioles, as well as cells present within the thickened interalveolar septa (Figure 22).

Regarding lung sections of bee venom pretreated rats (BVL group), they showed areas with moderate cytoplasmic immunoreaction in the epithelial cells lining the alveoli, bronchioles, blood vessels, as well as cells present within interalveolar septa. Other areas showed negative immunoreaction (Figure 23). Both bee propolis pretreated rats (BPL group) and combined therapy treated rats (CT group) showed moderate cytoplasmic immunoreaction in the epithelial cells lining the alveoli, bronchioles, as well as cells present within the thickened interalveolar septa (Figures 24\&25).

In bee venom only treated rats (BV group), they showed mild positive cytoplasmic immunoexpression in the epithelial cells lining the expanded alveoli, as well as in the cells of connective tissue septa (Figure 26). No remarkable difference was observed in bee propolis only treated rats (BP group) compared with group VI. 


\section{Morphometric results}

A significant increase $(\mathrm{P} \leq 0.05)$ in the mean area $\%$ and mean optical density of NF- $\mathrm{KB}$ immunoexpression in pancreatic and lung specimens was found in AP group as compared with the control group and other groups. Combined therapy group showed a non-significant increase in area $\%$ in pancreatic tissue and significant increase in lung tissues when compared with control group. Moreover, there was a non-significant difference in optical density in combined therapy group of both pancreatic and lung tissues when compared with control group (Tables $4 \& 5$ )

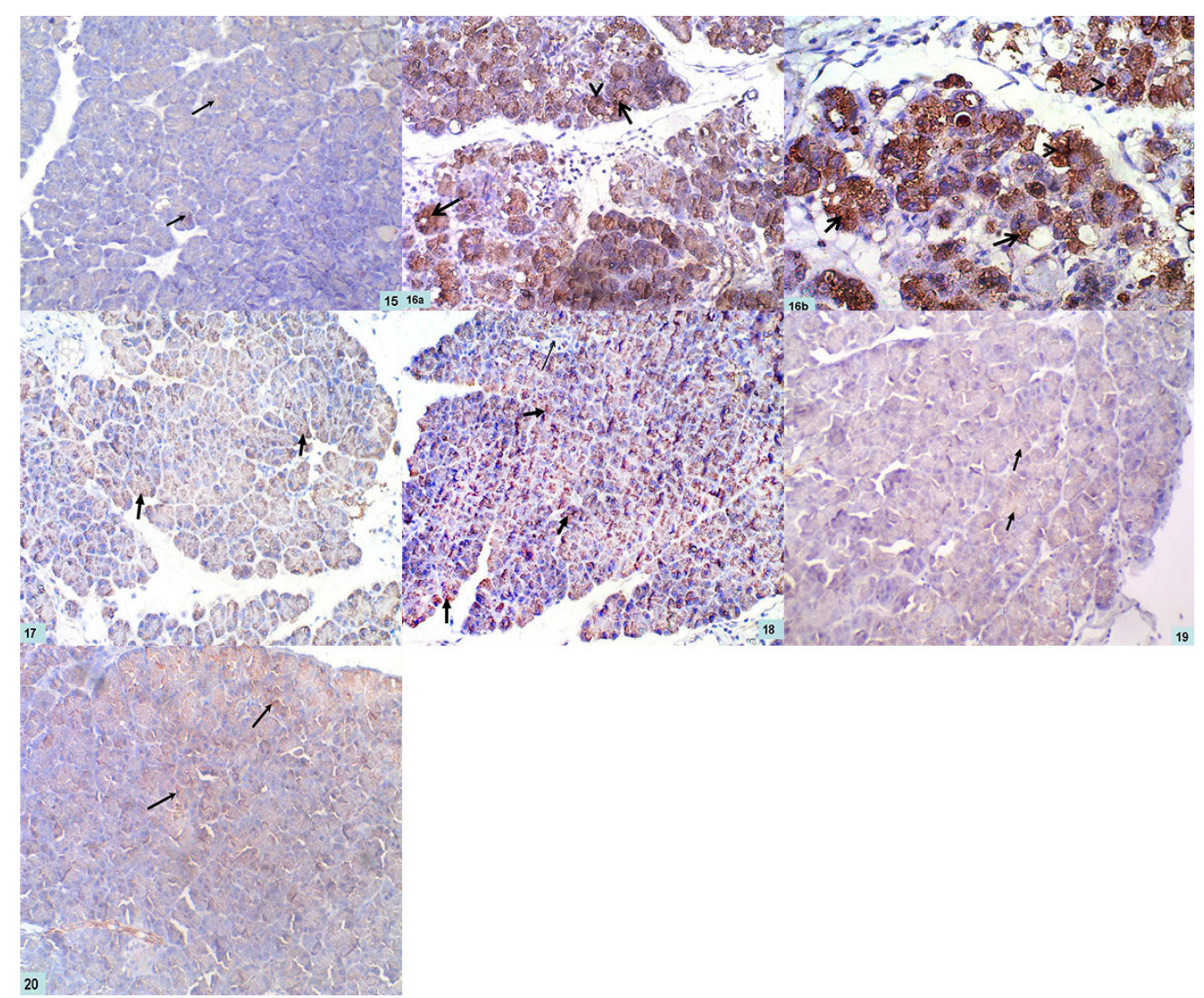

Figure 15 A photomicrograph of a section of a rat pancreas in group I (CG) showing mild cytoplasmic immunoexpression in the acinar cells (arrows). NF-KB; $\times 200$

Figures 16a\&b Photomicrographs of a section of a rat pancreas in group II (AP group) showing intense cytoplasmic (arrows) and nuclear immunoreactivity (arrow heads) in the acinar cells

a- NF-KB; $\times 200$

b- NF-KB; $\times 400$

Figure 17 A photomicrographs of a section of a rat pancreas in group III (BVL group) showing moderate cytoplasmic immunoreaction in the acinar cells (arrows).

NF-KB; $\times 200$

Figure 18 A photomicrograph of a section of a rat pancreas in group IV (BPL group) showing positive cytoplasmic immunoreaction in pancreatic acini (thick arrows) and negative immunoreaction in islet of Langerhans (thin arrow).

NF-KB; $\times 200$

Figure 19 A photomicrograph of a section of a rat pancreas in group V (CT group) showing positive cytoplasmic immunoreaction in pancreatic acini (arrows). $\mathrm{NF}-\mathrm{KB} ; \times 200$

Figure $20 \mathrm{~A}$ photomicrograph of a section of a rat pancreas in groups VI (BV group) showing mild immunoreaction in acinar cells (arrows). NF-KB; $\times 200$ 


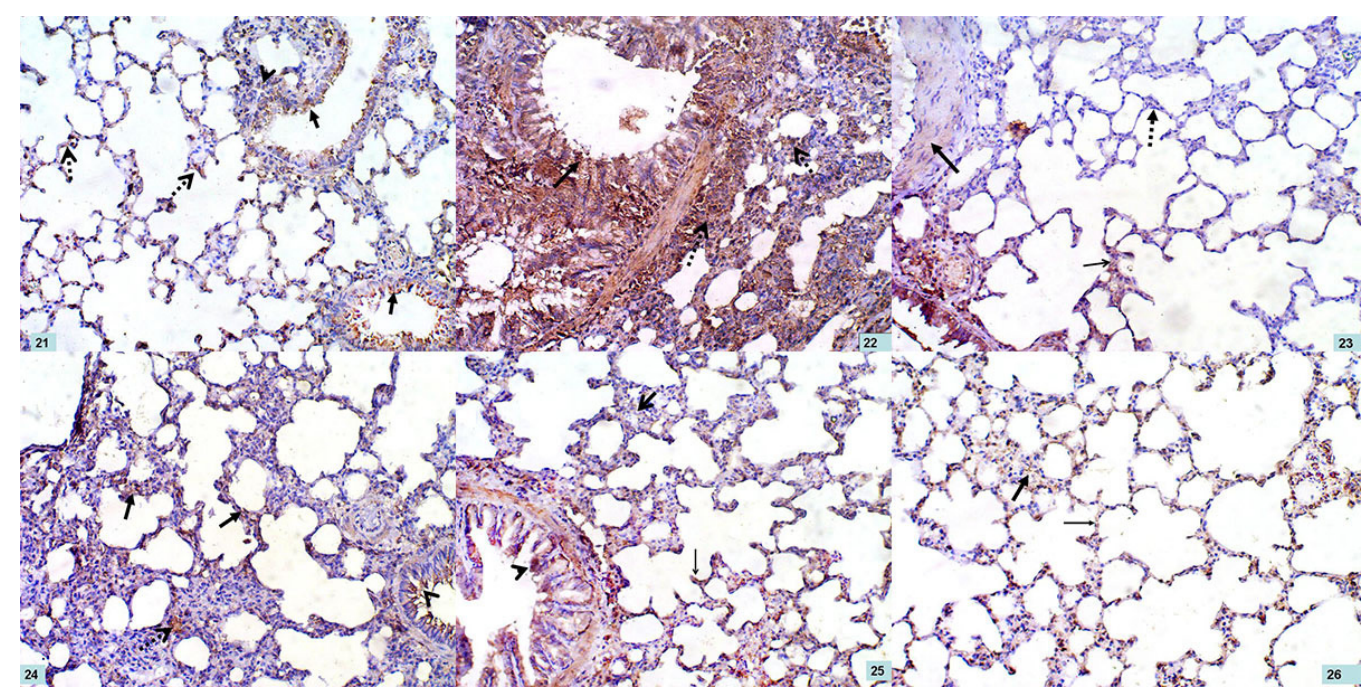

Figure 2I A photomicrograph of a section of a rat lung in group I (CG) showing mild positive cytoplasmic immunoexpression in the epithelial cells lining the expanded alveoli (dotted arrows), bronchioles (arrows), as well as in the cells of connective tissue septa (arrow head).

$\mathrm{NF}-\kappa \mathrm{B} ; \mathrm{x} 200$

Figure 22 A photomicrograph of a section of a rat lung in group II (AP group) showing intense cytoplasmic immunoreactivity in the epithelial cells lining the alveoli, bronchioles (arrow), as well as cells present within the thickened interalveolar septa (dotted arrows).

NF-KB; $\times 200$

Figure $23 \mathrm{~A}$ photomicrograph of a section of a rat lung in group III (BVL group) showing areas with moderate cytoplasmic immunoreaction in the epithelial cells lining the alveoli (thin arrow), bronchioles, blood vessels (thick arrow), as well as cells present within interalveolar septa. Other areas show negative immunoreaction (dotted arrow)

NF-KB; $\times 200$

Figure 24 A photomicrograph of a section of a rat lung in group IV (BPL group) showing moderate cytoplasmic immunoreaction in the epithelial cells lining the alveoli (arrows), bronchioles (arrow head), as well as cells present within the thickened interalveolar septa (dotted arrow).

$\mathrm{NF}-\kappa \mathrm{B} ; \mathrm{x} 200$

Figure 25 A photomicrograph of a section of a rat lung in group V (CT group) showing moderate cytoplasmic immunoreaction in the epithelial cells lining the alveoli (thin arrow), bronchioles (arrow head), as well as cells present within the thickened interalveolar septa (thick arrow).

NF-KB; $\times 200$

Figure 26 A photomicrograph of a section of a rat lung in groups VI (BV group) showing mild positive cytoplasmic immunoexpression in the epithelial cells lining the expanded alveoli (thin arrow), as well as in the cells of connective tissue septa (thick arrow).

NF-KB; $\times 200$

\section{Discussion}

Experimental acute pancreatitis have been induced by caerulein, L-arginine, choline deficient ethionine supplemented (CDE) diet, or sodium taurocholate in different animal models. These models vary in severity and have been used by the researchers to understand the pathogenesis of the disease and to study the effect of different therapeutic agents. ${ }^{26}$

Acute hemorrhagic necrotizing pancreatitis (AHNP) is a potentially fatal disease with very high morbidity and mortality rate. Acute lung injury (ALI) is the most serious complication of AHNP, but the link between AHNP and pulmonary damage is not fully understood. Many factors, such as oxygen free radicals, NF- $\mathrm{kB}$, nitric oxide (NO), cytokines and arachidonic acid metabolites may be related to AHNP and ALI. ${ }^{27,28}$ L-arginine (an essential amino acid) was previously used to induce severe necrotizing AP in rats. Uçmak et al., ${ }^{29}$ revealed that intraperitoneal injection of L-arginine induced acute pancreatitis in a rat by creating free oxygen radicals that damage the pancreas. The dose of 1-arginine used in this study was selected as an appropriate dose in producing acute pancreatitis with a peak effect within two to three days with the least mortality rates as higher doses has higher mortality rates and lowe $+r$ doses has a limited effect in producing pancreatitis. The choice of examining the specimens after 48 hours in AP group exposed to 1-arginine was based on a study of Wang et al..$^{30}$

The diagnosis of acute pancreatitis is based on many findings including laboratory investigations. The most important biomarkers are amylase, lipase, CRP, GGT and others. Regarding amylase enzyme, it is rapidly elevated within 6 hours of onset of disease. It remains at high levels for 3-5 days after reaching its peak. Despite its importance as a marker of pancreatitis, its return to normal level does not correlate with disappearance of clinical symptoms. Lipase increased within 3-6 hours of onset of disease and reaches its peak after 24 hours. It remains around 7-14 days before normalization. ${ }^{31-33}$

Concerning CRP, it is synthesized by hepatocytes and increased during inflammation. Cytokines like IL6 are potent stimulators of CRP synthesis. ${ }^{34,35} \mathrm{C}$ reactive protein is a factor which has a prognostic 
value for acute pancreatitis. It is used as a scoring parameter for severity of AP during its managment. ${ }^{36}$ It also has a predictive value regarding mortality that is associated with complications of AP. ${ }^{37}$

Another biomarker, GGT was used for diagnosis of alcoholic pancreatitis. Alcohol causes direct toxic effect on pancreatic acinar cells through induction of oxidative stress. ${ }^{38}$ So, GGT was investigated in this study as L-arginine induces acute pancreatitis by the same mechanism of alcohol. ${ }^{29}$ It is worth-mentioning that severe acute pancreatitis is accompanied by disorder of endocrine function. This is due to pancreatic islet injury including beta cells. ${ }^{39}$ So, measurement of serum glucose level in this study may be of great value.

Matrix metalloproteinase-9 (MMP-9) is a type IV collagenase. Its main function is extracellular matrix degradation. In the process of inflammation, MMP-9 causes vascular endothelial injury with subsequent migration and invasion of inflammatory cells, worsening the inflammatory response. Recent studies revealed that MMP-9 may act as a potential biomarker in acute pancreatitis. They have shown a strong relation between MMP-9 and development of pancreatic necrosis. So, it could be used as a marker of severity of the disease. ${ }^{40,41}$ In the present study, serum levels of amylase, lipase, CRP, GGT, glucose and MMP-9 gene expression were significantly elevated in the rats with untreated AP when compared with control and other groups, while total antioxidant level in pancreatic tissue was significantly reduced in AP group when compared with control and other groups.

These biochemical findings were in accordance with Fan et al., ${ }^{42}$ Mirmalek et al. ${ }^{43}$ and Wang et al., ${ }^{15}$ who detected high serum level of amylase and lipase in acute pancreatitis, Biradar et al. ${ }^{44}$ who showed elevated CRP in L-arginine induced pancreatitis; Moulali ${ }^{39}$ who revealed elevated GGT in alcoholic pancreatitis, Ucmak et al., ${ }^{29}$ who demonstrated low antioxidant levels and Hong et al., ${ }^{39}$ who revealed increased glucose level in severe acute pancreatitis due to beta cell injury. Ping et al. ${ }^{45}$ reported that MMP-9 gene expression was elevated with acute pancreatitis.

The pretreated groups with bee venom and propolis showed significant improvements in these parameters especially regarding total antioxidants in pancreatic tissues. There was a significant increase in its levels in all pretreated groups as compared with AP group. These results were consistent with previous studies which have revealed the decline of different biomarkers of acute pancreatitis by using bee venom ${ }^{16,17,46}$ and propolis. ${ }^{18}$ It is worth-mentioning that a recent study has reported that polyphenols from propolis inhibit MMP-9 gene expression and activity of activated macrophages in a dose dependent manner. ${ }^{47}$ Another study has revealed that melittin an apamine (the active substances in bee venom) significantly reduced MMP-9 gene expression. ${ }^{48}$

The ameliorating effect of bee products on these biomarkers could be attributed to their antioxidant properties by inhibiting formation of radicals, scavenging free radicals, preventing lipid peroxidation of membranes (thereby controlling membrane permeability), and causing an increased intracellular content of scavenger. ${ }^{49,50}$ They have also anti-inflammatory effect that interfere with the transduction cascade controlled by NF- $\mathrm{KB}$, a transcription factor for genes involved in cell survival, differentiation, inflammation, and growth. ${ }^{49-52}$ It is worth-mentioning that there was no significant difference between the pretreatment groups except as regarding TAC and MMP-9 expression where combined therapy group showed a significant difference. This indicated that combined therapy may have better effect. In spite of the marked improvement in the pretreatment groups; there was a significant difference between them and the control group. This might be due to the short duration or inappropriate dose of treatment.

In the present study, examination of hematoxylin \& eosin - stained pancreatic sections of AP group showed interstitial edema, congested blood vessels, acinar necrosis in the form of distortion and vacuolation of pancreatic acinar cells. They also demonstrated extravasation of RBCs (hemorrhage) and infiltration of mononuclear inflammatory cells within the dilated connective tissue septa. These results are in accordance with Wang et al., ${ }^{15}$ who demonstrated edema, acinar cell necrosis, hemorrhage, and inflammation after 48 and 72 hours from 1-arginine injection. Sayed et al., ${ }^{42}$ Fan et al., ${ }^{53}$ and Mirmalek et al. ${ }^{43}$ have shown the same results but by using different methods for inducing pancreatitis and different times of scarification.

It is worth-mentioning that under normal conditions, digestive enzymes and enzyme precursors known as zymogens are packed into zymogen granules. These granules release their content into the pancreatic duct after eating. In pancreatitis, a decrease in secretion into the duodenum in animals and humans is noted. This is due to decreased apical secretion of the acinar cells and disruption of the paracellular sealing in the pancreatic duct. These events allow the contents to leak into the paracellular space and redirect the secretion of the zymogen granules from the apical pole to the basolateral regions of the acinar cell, as shown by in-vitro and in-vivo animal studies. ${ }^{54}$ So, the degenerative changes of pancreatic acini may be due to autodigestion by inappropriately activated enzymes and lysosomal hydrolases. As a result of these necrotic changes, neutrophils are attracted to the site of inflammation. They release cytokines and cause interstitial edema that impairs blood flow and causes ischemia and acinar cell injury. ${ }^{55,56}$ Monocytes and macrophages also have an important role in the pathogenesis of acute pancreatitis. They migrate to the pancreatic interstitium from the circulation. They also produce cytokines and other inflammatory mediators. The degree of monocyte activity may be related to disease severity and the degree of local damage..$^{57,58}$

Pretreatment with bee venom and propolis in 1-arginine treated rats provided protection against the histopathological changes concerning pancreatic acini, inflammatory cellular infiltration and widening of connective tissue septa. As the mechanism of pancreatitis was reported to be due to premature activation and release of digestive enzymes, ${ }^{55,56}$ it would be appropriate to assume that bee venom and bee propolis would exert their therapeutic effect through delaying and decreasing the premature activation and release of pancreatic digestive enzymes. They might do this action through their antioxidant effect and restoration of the altered antioxidant defense system. They can reduce the levels of reactive oxygen species that might be responsible for its anti-inflammatory effects. ${ }^{49,50}$

The previous results were consistent with Seo et al., ${ }^{16}$ Yun et al., ${ }^{46}$ and Bae et al., ${ }^{17}$ who revealed that bee venom inhibited histological damage of pancreas. Results were also consistent with Buyukberber et al., ${ }^{18}$ who reported the ameliorating effect of caffeic acid phenethyl ester, one of the active components of propolis, on acute pancreatitis. Regarding morphological changes in hematoxylin \& eosin-stained lung specimens of AP group, there were edematous thickened interalveolar septa and dilated congested blood vessels with acidophilic hyaline exudate. There was also acidophilic material with cellular debris in bronchiolar lumen. Mononuclear inflammatory cellular infiltrate was noticed inside the lumen of bronchioles and in the thickened interalveolar septa. Collapsed alveoli were also observed. The 
previous findings were concomitant with that of Chen et al., ${ }^{59}$ who revealed inflammatory cell infiltration (predominantly neutrophils), pulmonary edema, and hemorrhage of alveoli and interstitial tissue. Other previous studies have shown similar findings. ${ }^{60-62}$

Previous studies have shown that neutrophils and leukocytes were attracted to the site of injury as early as 3 hours after induction of pancreatitis. Infiltrating polymorphonuclear neutrophils produce oxygen-free radicals and thus cause local and systemic complications. ${ }^{1,63}$ The pathophysiology of severe acute pancreatitis with acute lung injury is poorly understood. Researchers have hypothesized that during localized inflammation; cytokines may leak into the circulation and exceed the amount of soluble receptors, which may then lead to systemic inflammation. ${ }^{64}$

Pretreatment with bee venom and propolis in 1-arginine treated rats showed marked improvement in the form of expanded alveoli and thinning of interalveolar septa. Disappearance of congestion and inflammatory cellular infiltration were also observed in mixed therapy group. These results were consistent with that of Choi et al. ${ }^{65}$ who revealed efficiency of bee venom on diminishing bronchial inflammation in an OVA-induced allergic asthma murine model and with that of Ma et al., ${ }^{66}$ who reported the potency of Caffeic acid phenethyl ester in alleviating airway inflammation and remodeling in chronic asthma by balancing the airway microenvironment. This enforces the finding of anti-inflammatory and antioxidant effect of both bee venom and bee propolis. A significant increase in immunoreactivity of $\mathrm{NF}-\mathrm{\kappa B}$ (represented by area $\%$ and optical density) in pancreatic and lung specimens was observed in AP group as compared with the other groups. Previous studies have revealed the role of nuclear factor-kappa B (NF- $\mathrm{kB}$ ) activation as an early and central event in the progression of inflammation in AP. NF- $\kappa B$, is a molecule that links the initial acinar injury to systemic inflammation. So, direct NF- $\mathrm{kB}$ inhibition strategies were the target of many studies. ${ }^{67}$

This change in the immune reaction may be due to oxidative stress caused by L-arginine. Oxidative stress is known to stimulate transcription factors, including NF- $\kappa \mathrm{B}$ via phosphorylation of $\mathrm{I} \kappa \mathrm{B}$

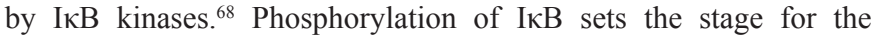
dissociation and nuclear translocation of NF- $\mathrm{kB}$. Then it binds to the corresponding DNA sequence of genes, inducing the expression of different inflammatory mediators such as iNOS and COX II. ${ }^{69}$

Several cytokines also have been found to be associated with the pathogenesis of pancreatitis. These include pro-inflammatory cytokines: tumour necrosis factor- $\alpha$ (TNF- $\alpha$ ), interleukin- 6 (IL-6). ${ }^{70}$ TNF- $\alpha$ is produced by blood monocytes and macrophages. It mediates the release of various inflammatory mediators and has a strong toxic effect. ${ }^{71} \mathrm{TNF} \alpha$ acts as NF- $\mathrm{KB}$ - dependent pro-inflammatory cytokine. It tends to be receptors that, in turn, activate NF-kB. So, $\mathrm{NF}-\mathrm{\kappa B}$ is important for the propagation and elaboration of cytokine responses. Moreover, TNF $\alpha$ is important for both local and systemic inflammation. It is also a potent inducer of NF- $\mathrm{kB} .{ }^{72}$

Although, nuclear localization of NF- $\mathrm{B}$ is considered as equivalent to NF- $\kappa B$ activation, it is difficult to determine whether immunohistochemical detection reflects its dynamic localization. However, similar to our study, previous researches have determined $\mathrm{NF}-\kappa \mathrm{B} / \mathrm{p} 65$ expression by immunohistochemical staining. ${ }^{73}$ The previous results were in accordance with Xiao et al. ${ }^{74}$ and Wang et al., ${ }^{30}$ who revealed increased immunoexpression of NF- $\mathrm{kB}$ in acinar cells in pancreatitis by using immunohistochemical and western immunoblot techniques and with Kan et al., ${ }^{73}$ who demonstrated increased immunoexpression of NF- $\mathrm{kB}$ in lung and pancreatic tissues in induced severe pancreatitis.

Pretreatment with bee venom and propolis in L-arginine treated rats significantly reduced $\mathrm{NF}-\kappa \mathrm{B}$ immunoreactivity. This improvement may be attributed to inhibition of NF- $\mathrm{kB}$ activation, with subsequent inhibition of cyclooxygenase and consequent inhibition of prostaglandin biosynthesis, free radical scavenging, inhibition of nitric oxide synthesis, reduction in the concentration of inflammatory cytokines and immunosuppressive activity. ${ }^{49-52}$

In acute pancreatitis, pro-inflammatory cytokines secreted from the pancreatic cells, vascular endothelial cells and tissue macrophages in the pancreas enter the circulation through the portal vein and the lymphatic system. They activate the vascular endothelium leading to micro-vascular leakage of the capillary veins and leukocyte migration into the tissues, as seen in experimental rat pancreatitis. Proinflammatory cytokines also activate the coagulation process in human patients which causes thrombosis in the small vessels of many organs. Both of these phenomena result in impaired tissue microcirculation. Thus, it may lead to organ failure in severe pancreatitis. ${ }^{75}$

So, changes occuring in acute lung injury involve endothelial barrier dysfunction, neutrophil and monocyte/macrophage activation, adhesion molecule expression and intracellular signaling. These can be executed by proteases derived from polymorphonuclear neutrophils (PMNs). This process seems to be driven by tumor necrosis factor (TNF)- $\alpha$ and monocyte chemoattractant protein (MCP)-1, with involvement of mast cells, at least during the initiation of leukocyte activation. So, it seems that inflammatory mediators may play a key role in the pathogenesis of acute lung injury. Moreover, active pancreatic enzymes in the circulation, released as a result of pancreatic injury, play a key role in the development of pulmonary complications of pancreatitis. ${ }^{76-78}$

\section{Conclusion}

Administration of bee venom and propolis in injection form either by S.C. or I.M. route was for rapid effect and high bioavailability. They have ameliorated both biochemical and histopathological parameters. The present study also showed that combined therapy was the most potent treatment. Finally, apitherapy could be helpful as prophylactic and/or therapeutic approach in AP.

\section{Acknowledgments}

None.

\section{Conflicts of interest}

The author declares there are no conflicts of interest.

\section{References}

1. Manohar M, Verma AK, Venkateshaiah SU, et al. Immunological Responses Involved In Promoting Acute and Chronic Pancreatitis. Clin Immunol Res. 2017;1(1):1-8

2. Uchendu Ik, Agu CE, Orji OC, et al. Review on diagnosis of acute pancreatitis. J Med Allied Sci. 2017;7(2):76-81.

3. Signoretti M, Valente R, Repici A, et al. Endoscopy-guided ablation of pancreatic lesions: Technical possibilities and clinical outlook. World $J$ Gastrointest Endosc. 2017;9(2):41-54. 
4. Binet Q, Dufour I, Agneessens E, et al. The second case of a young man with 1-arginine-induced acute pancreatitis. Clinical Journal of Gastroenterology. 2018;11(5):424-427.

5. Hasan MIA, Bakr AG, Shalkami AGS. Modulation of 1-arginine-induced acute pancreatitis by meloxicam and/or L-carnitine in rats. Int J Basic Clin Pharmacol. 2015;4(6):1247-1253.

6. Basa B, BelayW, Tilahun A, et al. Review on medicinal value of honeybee products: apitherapy. Advances in Biological Research. 2016;10(4):236-247.

7. Kocot J , Kiełczykowska M, Luchowska Kocot D, et al. Antioxidan Potential of Propolis, Bee Pollen, and Royal Jelly: Possible Medical Application. Oxid Med Cell Longev. 2018;2018:7074209.

8. Hyemin Gu, Woon Hae K, Hyun Jin A, et al. Therapeutic effects of bee venom on experimental atopic dermatitis. Molecular medicine reports. 2018;18(4):3711-3718

9. Shaldoum FM, Hassan MI, Mohammed S, et al. Natural Honey Bee venom Manipulates Human Immune Response. The Egyptian Journal of Hospital Medicine. 2018;72(4):4252-4258.

10. Sforcin JM. Biological Properties and Therapeutic Applications of Propolis. Phytother Res. 2016;30(6):894-905.

11. Ahangari Z, Naseri M, Vatandoost F. Propolis: chemical composition and its applications in endodontics. Iranian endodontic journal. 2018;13(3):285-292.

12. Cassileth BR. Chapter 36: Apitherapy. The Complete Guide to Complementary Therapies in Cancer Care: Essential Information for Patients, Survivors and Health Professionals. World Scientific. 2011.

13. Gupta RK, Stangaciu S. Apitherapy: holistic healing through the honeybee and bee products in countries with poor healthcare system. 2014 .

14. Gluck JP, Pasquale TD, Orlans B. Applied ethics in animal research :philosophy, regulation, and laboratory applications. 2002.

15. Wang N, Zhang F, Yang L, et al. Resveratrol protects against L-arginineinduced acute necrotizing pancreatitis in mice by enhancing SIRT1mediated deacetylation of $\mathrm{p} 53$ and heat shock factor 1 . Int J Mol Med. 2017;40(2):427-437.

16. Seo SW, Jung WS, Lee SE, et al. Effects of bee venom on cholecystokinin octapeptide-induced acute pancreatitis in rats. Pancreas. 2008;36(2):2229.

17. Bae GS, Heo KH, Park KC, et al. Apamin attenuated cerulein-induced acute pancreatitis by inhibition of JNK pathway in mice. Digestive Disease and Sciences. 2013;58(10):2908-2917.

18. Büyükberber M, Savaş MC, Bağci C, et al. The beneficial effect of propolis on cerulein-induced experimental acute pancreatitis in rats. The Turkish Journal of Gastroenterology. 2009;20(2):122-128.

19. Fisher CL, Nakamura R. Latex serology test for detection of $\mathrm{C}$ reactive protein. Am J Clin Pathol. 1976;66:840-847.

20. Caraway WT. A stable starch substrate for the determination of amylase in serum and other body fluids. American Journal of Clinical Pathology. 1959;32(1):97-99.

21. Lott J, Patel ST, Sawhney AK, et al. Assays of serum lipase: Analytical and clinical considerations. Clinical Chemistry. 1986;32(7):1290-1302.

22. Szasz G. New substrates for measuring gamma-glutamyl transpeptidase activity. Z Klin Chem Klin Biochem. 1974;12(5):228

23. Weissman M, Klien B. Evaluation, of glucose determination In untreated serum samples. Clin Chem. 1958;4(5):420-422.
24. Caraway WT, Watts NB. Carbohydrates. In: Tietz NW, editor Fundamentals of Clinical Chemistry. 3rd edn. Philadephia WB saunders. $1987 ; 1422-1447$.

25. Miller NJ, Rice Evans C, Davies MJ, et al. A novel method for measuring antioxidant capacity and its application to monitoring the antioxidant status in premature neonates. Clin Sci. 1993;84(4):407-412.

26. Zhao JB, Liao DH, Nissen TD. Animal models of pancreatitis: Can it be translated to human pain study? World $J$ Gastroenterology. 2013;19(42):7222-7230.

27. Liu NJ, Chapman R, Lin Y, et al. Phospholipase A2 as a point of care alternative to serum amylase and pancreatic lipase. Nanoscale. 2016;8(23):11834-11839.

28. Buchwalow I, Schnekenburger J, Atiakshin D, et al. Oxidative stress and $\mathrm{NO}$ generation in the rat pancreatitis induced by pancreatic duct ligation. Acta Histochem. 2017;119(3):252-256.

29. Uçmak F, Ekin N, İbiloğlu İ, et al. Prophylactic Administration of Silybin Ameliorates L-Arginine-Induced AcutePancreatitis. Med Sci Monit. 2016;22:3641-3646.

30. Wang YR, Tian FL, Yan MX, et al. Sulfasalazine inhibits inflammation and fibrogenesis in pancreas via NF- $\mathrm{B}$ signaling pathway in rats with oxidative stress-induced pancreatic injury. Drug Design, Development and Therapy. 2016;10:1743-1751.

31. Clavien PA, Robert J, Meyer P, et al. Acute pancreatitis and normoamylasemia. Not an uncommon combination. Annals of Surgery. 1989;210(5):614-620

32. Matull WR, Pereira SP, O Donohue JW. Biochemical markers of acute pancreatitis. Journal of Clinical Pathology. 2006;59(4):340-344.

33. Lippi G, Valentino M, Cervellin G. Laboratory diagnosis of acute pancreatitis: in search of the Holy Grail. Critical Reviews in Clinical Laboratory Sciences. 2012;49(1):18-31.

34. Allin KH, Nordestgaard BG. Elevated C-reactive protein in the diagnosis, prognosis, and cause of cancer. Crit Rev Clin Lab Sci. 2011;48(4):155-170.

35. Ansar W, Ghosh S. C-reactive protein and the biology of disease. Immunol Res. 2013;56(1):131-142.

36. Sato T, Ohno K, Tamamoto T, et al. Assesment of severity and changes in C-reactive protein concentration and various biomarkers in dogs with pancreatitis. J Vet Med Sci. 2017;79(1):35-40.

37. Tachyla SA, Marochkov AV, Lipnitski AL, et al. The prognostic value of procalcitonin, C-reactive protein and cholesterol in patients with an infection and multiple organ dysfunction. Korean J Anesthesiol. 2017;70(3):305-310.

38. Moulali D. A study on gamma glutamyle transferase and amylase levels in chronic alcoholics with hepatitis. Int JSci Res Pub. 2015;5(11):758764.

39. Hong YP, Guo WY, Wang WX, et al. Corrigendum to "4-Phenylbutyric Acid Attenuates Pancreatic Beta-Cell Injury in Rats with Experimental Severe Acute Pancreatitis. Int J Endocrinol. 2018;2018:6307830.

40. Guo J, Xue P, Yang XN, et al. Serum matrix metalloproteinase-9 is an early marker of pancreatic necrosis in patients with severe acute pancreatitis. Hepato-Gastroenterology. 2012;59(117):1594-1598.

41. Halade GV, Jin YF, Lindsey ML. Matrix metalloproteinase (MMP)-9: a proximal biomarker for cardiac remodeling and a distal biomarker for inflammation. Pharmacol Ther. 2013;139(1):32-40.

42. Fan YT, Yin GJ, Xiao WQ, et al. Rosmarinic Acid Attenuates Sodium Taurocholateinduced Acute Pancreatitis in Rats by Inhibiting Nuclear Factor-кB Activation. Am J Chin Med. 2015;43(6):1117-1135. 
43. Mirmalek SA, Gholamrezaei Boushehrinejad A, Yavari $\mathrm{H}$, et al Antioxidant and Anti-Inflammatory Effects of Coenzyme Q10 on L-Arginine-Induced Acute Pancreatitis in Rat. Oxid Med Cell Longev. 2016:5818479.

44. Biradar S, Veeresh B. Protective effect of lawsone on L-Arginine induced acute pancreatitis in rats. Indian Journal of Experimental Biology. 2013;51(3):256-261.

45. Ping C, Yongping Z, Minmin Q, et al. Activated proteinC improves the severity of severe acute pancreatitis via up-regulating the expressions of endothelial cell protein C receptor and thrombomodulin. Dig Dis Sci. 2010;55(6):1599-1609.

46. Yun SW, Bae GS, Kim MS, et al. Melittin inhibits cerulein-induced acute pancreatitis via inhibition of the JNK pathway. Int Immunopharmacol. 2011;11(12):2062-2072.

47. Saavedra N, Cuevas A, Cavalcante MF, et al. Polyphenols from Chilean Propolis and Pinocembrin Reduce MMP-9 Gene Expression and Activity in Activated Macrophages. BioMed Research International. 2016;6505383.

48. Shin SH, Ye MK, Choi SY, et al. The Effects of Melittin and Apamin on Airborne Fungiinduced Chemical Mediatorand Extracellular Matrix Production from Nasal Polyp Fibroblasts. Toxins (Basel). 2017;9(11):348

49. Hemieda FAE, El Kholy WM, El Habibi EM, et al. Influence of propolis on oxidative stress, inflammation and apoptosis in streptozotocin induced diabetic rats. International Journal of Advanced Research. 2015;3(7):831-845

50. Sobral F, Sampaio A, Falcao S, et al. Chemical characterization, antioxidant, anti-inflammatory and cytotoxic properties of bee venom collected in Northeast Portugal. Food ChemToxicol. 2016;94:172-177.

51. Araujo MAR, Libério SA, Guerra RNM, et al. Mechanisms of action underlying the anti-inflammatory and immunomodulatory effects of propolis: a brief review. Revista Brasileira de Farmacognosia. 2012;22(1):208-219.

52. Gu SM, Park MH, Hwang CJ, et al. Bee venom ameliorates lipopolysaccharide- induced memory loss by preventing NF-kappaB pathway. J Neuro inflammation. 2015;12:124.

53. Sayed SSE, Abdel Kader DH. Histological and immunohistochemical study of the role of glutamine on lipopolysaccharide-induced pancreatitis and associated lung injury. The Egyptian Journal of Histology 2013;36(1):50-59.

54. Gaisano HY, Gorelick FS. New insights into the mechanisms of pancreatitis. Gastroenterology. 2009;136(7):2040-2044.

55. Abdulla A, Awla D, Thorlacius H, et al. Role of neutrophils in the activation of trypsinogen in severe acute pancreatitis. J Leukoc Biol. 2011;90(5):975-982.

56. Jones MJ, Hall OM, Kaye AM, et al. Drug-Induced Acute Pancreatitis: A Review. Ochsner J. 2015;15(1):45-51.

57. Perides G, Weiss ER, Michael ES, et al. TNF-alpha-dependent regulation of acute pancreatitis severity by Ly-6C(hi) monocytes in mice. $J$ Biol Chem. 2011;286(15):13327-13335.

58. Mayerle J, Dummer A, Sendler M, et al. Differential roles of inflammatory cells in pancreatitis. $J$ Gastroenterol Hepatol. 2012;27(Suppl 2):47-51.

59. Chen JI, Qingping Cai QP, Shen PJ, et al. Netrin-1 protects against L-arginine-induced acute pancreatitis in mice. PLOS ONE. 202;7(9):46201

60. Zhang H, Neuhofer P, Song L, et al. IL-6 trans-signaling promotes pancreatitis-associated lung injury and lethality. Journal of Clinical Investigation. 2013;123(3):1019-1031.
61. Aziz NM, Kamel MY, Rifaai RA. Effects of hemin, a heme oxygenase-1 inducer in L-arginine-induced acute pancreatitis and associated lung injury in adult male albino rats. Endocr Regul. 2017;51(1):20-30

62. Nader MA, Wagih HM. Nilotinib, a tyrosine kinase inhibitor exhibits protection against acute pancreatitis-induced lung and liver damage in rats. Naunyn Schmiedebergs Arch Pharmacol. 2017;390(3):291-300.

63. Beger HG, Gansauge, Mayer JM. The role of immunocytes in acute and chronic pancreatitis: when friends turn into enemies. Gastroenterology. 2000;118(3):626-629.

64. Castellheim A, Brekke OL, Espevik T, et al. Innate immune responses to danger signals in systemic inflammatory response syndrome and sepsis. Scandinavian Journal of Immunology. 2009;69(6):479-491.

65. Choi MS, Park S, Choi T, et al. Bee venom ameliorates ovalbumin induced allergic asthma via modulating CD4+CD25+ regulatory T cells in mice. Cytokine. 2013;61(1):256-265.

66. Ma Y, Zhang JX, Liu YN, et al. Caffeic acid phenethyl ester alleviates asthma by regulating the airway microenvironment via the ROSresponsive MAPK/Akt pathway. Free Radic Biol Med. 2016;101:163175

67. Jakkampudi A, Jangala R, Reddy BR, et al. NF- $\kappa \mathrm{B}$ in acute pancreatitis: Mechanisms and therapeutic potential. Pancreatology. 2016;16(4):477488 .

68. Sun SC. The noncanonical NF- $\kappa \mathrm{B}$ pathway. Immunol Rev. 2012;246(1):125-140.

69. Murakami Y, Yuhara K, Takada N, et al. Effect of melatonin on cyclooxygenase-2 expression and nuclear factor-kappa $\mathrm{B}$ activation in RAW264.7 macrophage-like cells stimulated with fimbriae of Porphyromonas gingivalis. In Vivo. 2011;25(4):641-648.

70. Shen Y, Cui N, Miao B, et al002E Immune dysregulation in patients with severe acute pancreatitis. Inflammation. 2011;34(1):36-42.

71. Aoun E, Chen J, Reighard D, et al. Diagnostic accuracy of interleukin-6 and interleukin- 8 in predicting severe acute pancreatitis: a meta-analysis. Pancreatology. 2009;9(6):777-785.

72. Hayden MS, Ghosh S. NF-кB in immunobiology. Cell Res. 2011;21(2):223-244.

73. Kan S, Zhou H, Jin C, et al. Effects of PDTC on NF- $\kappa$ B expression and apoptosis in rats with severe acutepancreatitis associated lung injury. Int J ClinExp Med. 2015;8(3):3258-3270.

74. Xiao WQ, Yin GJ, Fan YT, et al. Catalpol ameliorates sodium taurocholate-induced acute pancreatitis in rats via inhibiting activation of nuclear factor kappa B. Int J Mol Sci. 2014;15(7):11957-11972.

75. Kylanpaa ML, Repo H, Puolakkainen PA. Inflammation and immunosuppression in severe acute pancreatitis. World Journal of Gastroenterology. 2010;16(23):2867-2872

76. Browne GW, Pitchumoni CS. Pathophysiology of pulmonary complications of acute pancreatitis. World Journal of Gastroenterology. 2006;12(44):7087-7096

77. Zhou MT, Chen CS, Chen BC, et al. Acute lung injury and ARDS in acute pancreatitis: Mechanisms and potential intervention. World Journal of Gastroenterology. 2010;16(17):2094-2099.

78. Petrie A, Sabin C. Medical statistics at a glance. 2nd edn. In: Sugden M, Moore K. editors. Blackwell Publishing LTD, USA. 2005. 